\title{
Characterization of Fusarium Strains Recovered From Wheat With Symptoms of Head Blight in Kentucky
}

S. Bec, Department of Plant Pathology, University of Kentucky, Lexington, KY 40546-0312; T. Ward, Bacterial Foodborne Pathogens and Mycology Research Unit, USDA-ARS, Peoria, IL 61604-3999; M. Farman, Department of Plant Pathology, University of Kentucky, Lexington, KY 40546-0312; K. O'Donnell, Bacterial Foodborne Pathogens and Mycology Research Unit, USDA-ARS, Peoria, IL 61604-3999; D. Hershman, Department of Plant Pathology, University of Kentucky, Lexington, KY 40546-0312; D. Van Sanford, Department of Plant and Soil Sciences, University of Kentucky, Lexington, KY 40546-0312; and L. J. Vaillancourt, Department of Plant Pathology, University of Kentucky, Lexington, KY 40546-0312

\begin{abstract}
Bec, S., Ward, T., Farman, M., O’Donnell, K., Hershman, D., Van Sanford, D., and Vaillancourt, L. J. 2015. Characterization of Fusarium strains recovered from wheat with symptoms of head blight in Kentucky. Plant Dis. 99:1622-1632.

Fusarium graminearum species complex (FGSC) members cause Fusarium head blight (FHB) of wheat (Triticum aestivum L.) and small grains in the United States. The U.S. population is diverse and includes several genetically distinct local emergent subpopulations, some more aggressive and toxigenic than the majority population. Kentucky is a transition zone between the Mid-Atlantic and Midwestern wheat production areas. Sixty-eight Fusarium strains were isolated from symptomatic wheat heads from central and western Kentucky and southern Indiana in 2007. A multilocus genotyping assay and a variety of additional molecular markers, including some novel markers developed using the $F$. graminearum genome sequence, were used to characterize the pathogen

population. Five of the isolates were identified as members of two non-FGSC species, $F$. acuminatum and $F$. cf. reticulatum, but they did not cause symptoms in greenhouse tests. All the FGSC isolates belonged to the 15-ADON chemotype of $F$. graminearum. Comparative genetic analysis using variable nuclear tandem repeat (VNTR) markers indicated that the population in Kentucky and Indiana belonged to the dominant North American population, with some diversification likely due to local evolution. Telomere and RFLP fingerprinting markers based on repetitive sequences revealed a high degree of genetic diversity within the population, with unique genotypes found at each location, and multiple genotypes isolated from the same head.
\end{abstract}

Fusarium head blight (FHB) is one of the most economically important diseases of wheat (Triticum aestivum L.) and other small grains worldwide (25). In the upper Midwestern United States, losses due to FHB epidemics between 1998 and 2000 totaled $\$ 2.5$ billion $(16,31,32)$. In 2003 there was a severe epidemic on soft red winter wheat (SRWW) throughout the southeastern United States, resulting in losses worth approximately $\$ 15$ million (6). In addition to reducing grain yields, FHB also results in contamination of the grain with a variety of trichothecene mycotoxins that are harmful to animal and human health $(18,49,63)$. During another severe FHB epidemic that occurred in Kentucky in 2009, deoxynivalenol (DON) levels were reported to be more than 17 -fold higher than normal (25).

Isolates of the fungal genus Fusarium causing the majority of FHB around the world are classified as members of the $F$. graminearum species complex (FGSC). The FGSC was previously considered to be a single panmictic species; however, multilocus molecular phylogenetic analyses have revealed at least 16 genetically distinct species within the FGSC, including $F$. graminearum Schwabe, identified as the primary cause of FHB in the United States $(34,36,44,52)$. Members of the FGSC produce type B trichothecene mycotoxins, including DON and nivalenol (NIV), and their respective acetylated forms. Three strain-specific profiles of trichothecene metabolites (chemotypes) have been described within the FGSC: $15 \mathrm{ADON}$ strains producing primarily DON and 15-acetyl-deoxynivalenol, 3ADON strains producing primarily DON and 3-acetyl-deoxynivalenol, and

Corresponding author: L. J. Vaillancourt, E-mail: vaillan@uky.edu

*The $\boldsymbol{e}$-Xtra logo stands for "electronic extra" and indicates that one supplementary table and two supplementary figures are included in the online edition.

Accepted for publication 20 October 2014.

http://dx.doi.org/10.1094/PDIS-06-14-0610-RE

(C) 2015 The American Phytopathological Society
NIV strains producing primarily NIV and acetyl-derivatives of NIV $(27,61)$. Most North American (NA) strains produce primarily $15-\mathrm{ADON}$, but there are regionally defined populations in NA, as well as populations outside of NA, in which 3-ADON and NIV chemotypes dominate $(8,9,13,14,21,30,41,42,48,52,62)$. Chemotypespecific genetic variation has been identified within and near genes that are responsible for chemotype differences, and can be used to predict chemotypes by molecular tests that determine trichothecene genotypes $(61,62)$.

The degree of pathogenically-significant chemotypic and genotypic variation that exists in the NA population of $F$. graminearum has important implications for the durability of FHB management and resistance breeding efforts in the United States. Although it has generally been assumed that new sources of resistance will be broadly effective against diverse isolates of the pathogen from across the country $(66,67)$, this belief has been challenged recently through data that demonstrate the existence of genetically distinct populations in several regions of the United States and Canada, including ones that differ in aggressiveness and toxigenicity from the majority populations $(12-14,44,52,62)$. It has been hypothesized that these subpopulations resulted from localized adaptive shifts, possibly in response to deployment of scab resistant wheat varieties or the introduction and spread of non-native pathogen populations $(12-14,44,52,62)$.

Kentucky represents a transition zone between the Mid-Atlantic and Midwestern wheat production areas. It is potentially a "hot spot" for mixing among $F$. graminearum genotypes adapted to the surrounding wheat- and corn (Zea mays L.)-producing regions. The half million acres of SRWW produced annually in Kentucky represent a critical source of capital for grain producers in the state. To assure an efficient cropping system and adequately utilize the available growing season, almost the entire Kentucky winter wheat crop is planted in a rotation following corn. Stalk and ear rot diseases, also caused by members of the FGSC, are common in corn (25), and the pathogen's persistence, combined with the prevalence of no-till or minimal tillage cropping systems, puts Kentucky wheat at a high risk for FHB. There has been only one previous study that included 
Fusarium strains causing FHB on SRWW in Kentucky (48). Results of that study indicated that the pathogen population in the state belonged primarily ( $>99 \%$ ) to the 15 -ADON chemotype. The purpose of the work described here was to characterize the structure and diversity of the Kentucky pathogen population in more detail, and to compare it with several previously characterized populations from other regions of NA. A variety of molecular markers, including newly developed restriction fragment length polymorphism (RFLP) fingerprinting markers derived from the $F$. graminearum genome sequence, were used to evaluate genetic diversity among a group of Fusarium strains isolated from symptomatic wheat heads collected from four locations in central and western Kentucky, and one location in neighboring southern Indiana.

\section{Materials and Methods}

Isolation and culture of fungal strains. The fungal isolates used in this study were recovered from SRWW heads displaying typical symptoms of FHB. The samples were collected in the spring of 2007 from four locations across Kentucky: Lexington, in Fayette Co. (1 field); Princeton, in Caldwell Co. (2 fields); Owensboro, in Daviess Co. (1 field); and Logan Co. (1 field). Samples were also collected from one location in southern Indiana (Hartfield, in Spencer Co.), just across the Ohio River from Owensboro. Between four and six symptomatic wheat heads were collected from each location. Samples were disinfested in $10 \%$ bleach with agitation for $10 \mathrm{~min}$, followed by three washes in sterile water. Small sections from the edges of lesions were plated on acidified potato dextrose agar (PDA) (1 $\mathrm{ml}$ of $85 \%$ lactic acid per 1 liter of PDA). All isolates were single-spored and stored on silica at $-80^{\circ} \mathrm{C}(57)$. All strains were routinely cultured on PDA at $23^{\circ} \mathrm{C}$ under constant white light. Asexual spores for wheat inoculations were produced by growing the isolates for 7 days at $23^{\circ} \mathrm{C}$ under continuous light on mung bean agar media (1).

DNA extraction. An 8-mm agar plug was taken from the edge of an actively-growing colony of Fusarium and placed in $5 \mathrm{ml}$ of YEPD medium ( $20 \mathrm{~g}$ dextrose, $20 \mathrm{~g}$ bacto-peptone, $10 \mathrm{~g}$ yeast extract/liter). Cultures were incubated at $25^{\circ} \mathrm{C}$ for 5 to 7 days with shaking at $250 \mathrm{rpm}$. Mycelia were harvested by decanting cultures onto sterile paper and blotting the excess liquid. The mycelia were flash-frozen in liquid nitrogen and stored at $-80^{\circ} \mathrm{C}$ prior to further manipulation. Frozen mycelia were lyophilized and then pulverized in individual 2-ml Eppendorf tubes using a mini-pestle, or in 96-deep well plates using a 2000 GENO Grinder (Spex Certiprep) (500 strokes/s for $30 \mathrm{~s}$ ). One milliliter of warm lysis buffer $(0.5 \mathrm{M} \mathrm{NaCl}, 1 \%$ SDS, $10 \mathrm{mM}$ Tris $\mathrm{HCl}, \mathrm{pH} 7.5,10 \mathrm{mM}$ EDTA) was added per 100 to $200 \mathrm{mg}$ of pulverized fungal tissue, and the samples were incubated at $65^{\circ} \mathrm{C}$ for $30 \mathrm{~min}$, vortexing once during the incubation. After incubation the samples were transferred into individual tubes containing $660 \mu \mathrm{l}$ phenol-chloroform-isoamyl alcohol (25:24:1), mixed by inverting 4 to 6 times, and then incubated at $65^{\circ} \mathrm{C}$ for an additional $30 \mathrm{~min}$. The samples were centrifuged in a tabletop centrifuge for 20 min at maximum speed to separate the phases. DNA was precipitated from the aqueous phase by using 1 vol. isopropanol, and the pellet was washed twice with $70 \%$ ethanol. The pellet was dissolved in $100 \mu \mathrm{l}$ of TE, $\mathrm{pH}$ 7.9 , plus $2 \mu \mathrm{l}$ of a $5 \mathrm{mg} / \mathrm{ml}$ solution of RNase A, at $65^{\circ} \mathrm{C}$ for $1 \mathrm{~h}$. Between 1 and $5 \mu \mathrm{g}$ of each DNA sample was digested with appropriate restriction enzymes (RE) and used in Southern hybridizations (50) for evaluation of transformant and wild-type strains.

Multilocus genotyping (MLGT). Members of the FGSC were simultaneously identified to species and trichothecene genotype via multilocus genotyping (MLGT) using a Luminex 100 flow cytometer as described previously (62). A 48-probe version of the MLGT assay $(35,44,62,65)$ was used to interrogate species and trichothecene chemotype-specific genetic variation in six genes.

Comparative analyses of population structure and diversity. Genetic variation at eight variable number tandem repeat (VNTR) loci (54) was determined for the Kentucky and Indiana $F$. graminearum isolates. VNTR amplifications were performed in three multiplex reactions using fluorescently labeled forward primers as previously described (62). Amplification products were detected and scored using an ABI3100 Genetic Analyzer with GENEMAPPER 3.7 software (Applied Biosystems). To assess population structure and diversity in relation to previously characterized populations from NA, VNTR data from the Kentucky and Indiana isolates were combined with previously published $(14,62)$ data for isolates collected in the Upper Midwest of the United States (UMW, $n=47$ ), western Canada (WCAN, $n=104$ ), and the Canadian maritime province of Prince Edward Island (PEI, $n=26$ ).

Population structure was investigated using the Bayesian modelbased clustering procedure implemented in STRUCTURE 2.3 (37), which assigns multilocus genotypes to user-defined $K$ population clusters. Analyses were performed for values of $K$ between 1 and 10 using the admixture model with independent allele frequencies and 100,000 Markov Chain Monte Carlo (MCMC) iterations following a "burn-in" period of 10,000 iterations. The mean number of pairwise differences between haplotypes $(\pi)$, the average gene diversity across loci $(H)$, and $F_{S T}$-based genetic distances were estimated in ARLEQUIN 3.5 (10). Pairwise $F_{S T}$ distances were calculated based on the number of different alleles method, and the significance of genetic differentiation was assessed using 1,000 permutations. The $F_{S T}$ distance matrix was used to infer relationships among populations via the neighbor-joining method as implemented in MEGA 6 (55).

Telomere probe. A telomere-specific probe (TTAGGG)n was generated using the PCR protocol described in Schechtman et al. (45) and Pfusion polymerase. Twenty picomoles of each primer were added to the PCR mix along with the manufacturer's recommended buffer. The thermocycling protocol consisted of 35 cycles of denaturation for $30 \mathrm{~s}$ at $94^{\circ} \mathrm{C}$, annealing for $30 \mathrm{~s}$ at $50^{\circ} \mathrm{C}$, and extension for $60 \mathrm{~s}$ at $72^{\circ} \mathrm{C}$; followed by a final $2 \mathrm{~min}$ extension at $72^{\circ} \mathrm{C}$. PCR products were separated on a $1 \%$ agarose gel. DNA with a size range of between 1.5 and $2 \mathrm{~kb}$ was excised and purified with a gel extraction kit (QIAquick, Qiagen cat. \#28704). The purified product (50 to $80 \mathrm{ng}$ ) was labeled using the Prime-a-gene labeling system (Promega, cat. \#U1100) and used for Southern hybridization analysis.

Repetitive fingerprinting probes. Repetitive motifs present in the genomic DNA sequence of $F$. graminearum strain PH-1 were identified by comparing the whole genome sequence of PH-1 (7) against itself using BLAST. The genome can be downloaded from the Fusarium comparative database website, www.broadinstitute. org/annotation/genome/fusarium_group/MultiHome.html. PCR primers (Table 1) were designed to amplify $\sim 500$ bp regions encompassing

Table 1. Primers used to produce molecular probes or markers used for this study

\begin{tabular}{|c|c|c|c|}
\hline Primer name & Type of marker & RE $^{\mathbf{a}}$ used & Primer sequences $\left(5^{\prime}-3^{\prime}\right)$ \\
\hline REP1.52F & RFLPb & BsoBI & GGTTCATGAAGACATTGGTC \\
\hline REP1.52R & RFLP & BsoBI & TGATCCCGGTCTACTACATC \\
\hline REP1.92F & RFLP & BsoBI & GTCACCAAAGTTCGGTTCT \\
\hline REP1.92R & RFLP & BsoBI & CGGTTATGCAATCTGTTCTT \\
\hline EcoRI3F & CAPS $^{c}$ & EcoRI & GGTTCGGTGAGTCTTTAAGCCCC \\
\hline EcoR13R & CAPS & EcoRI & CGGCTTGAGGGTTTTCGAGC \\
\hline Pst $\mathrm{I} 2 \mathrm{~F}$ & CAPS & Pst I & TCGACTTGAGAGACAACCGAGCA \\
\hline Pst $12 \mathrm{R}$ & CAPS & Pst $\mathrm{I}$ & TCAAAGGGCTTGGAGGAGAGTCA \\
\hline
\end{tabular}

\footnotetext{
a Restriction enzyme

b Restriction fragment length polymorphism

${ }^{c}$ Cleaved amplified polymorphic sequence.
} 
two of the repetitive sequences. The PCR conditions used to create the probes consisted of $3 \mathrm{~min}$ of denaturation at $94^{\circ} \mathrm{C}$; followed by 35 cycles of denaturation for $30 \mathrm{~s}$ at $94^{\circ} \mathrm{C}, 15 \mathrm{~s}$ of annealing at $55^{\circ} \mathrm{C}$, and $40 \mathrm{~s}$ of extension at $72^{\circ} \mathrm{C}$; and a final extension of $7 \mathrm{~min}$ at $72{ }^{\circ} \mathrm{C}$. Amplicons were labeled with ${ }^{32} \mathrm{P}$ using the Prime-a-gene labeling kit, and used as probes for Southern hybridization analysis. Five hundred nanograms of the genomic DNA isolated from the fungal strains was digested with the RE $B s o B I$. The DNA fragments were separated on a $0.8 \%$ agarose gel, transferred to a charged nylon membrane, and probed with the radioactively labeled probes.

Analysis of RFLP data. The RFLP data were coded as dominant markers, either as presence (" 1 ") or absence ("0") of the signal, and recorded in a matrix set. The data matrix was analyzed by using the Statistical Analysis Software (SAS Entrprise Guide 5.1) package to generate Jaccard's similarity coefficients for the construction of a dendrogram using the unweighted pair group method with arithmetic average (UPGMA) procedure. Only a single clone representing each fingerprint pattern was included in the analysis.

Cleaved amplified polymorphic sequences (CAPS) markers. Cleaved amplified polymorphic sequences (CAPS) markers were generated by using a list of single-nucleotide polymorphisms (SNPs) differentiating PH-1 and Gz3639 (7), available from www.broadinstitute. org/annotation/genome/fusarium_group/MultiHome.html. SNPs within EcoRI or PstI restriction sites were identified, and $\sim 500$ bp segments spanning two of these SNP loci were amplified using the primer sets listed in Table 1. PCR amplifications contained Phusion polymerase (Finnzymes F-530S) and other components according to the manufacturer's instructions. The thermocycling protocol consisted of initial denaturation for $1 \mathrm{~min}$ at $94^{\circ} \mathrm{C}$; followed by 35 cycles of $30 \mathrm{~s}$ denaturation at $94^{\circ} \mathrm{C}, 20 \mathrm{~s}$ annealing at $68^{\circ} \mathrm{C}$, and $45 \mathrm{~s}$ extension at $72^{\circ} \mathrm{C}$; followed by a final $7 \mathrm{~min}$ extension cycle at $72^{\circ} \mathrm{C}$. Three microliters of each PCR amplicon was used for each restriction reaction. Restriction reactions used Invitrogen RE EcoRI (Invitrogen cat. \#15202-015) and PstI (Invitrogen cat. \# 15215-015) according to the manufacturer's instructions. Restriction reactions were separated on a $1 \%$ agarose gel for analysis.

Sexual crosses. Strain mat $1-1-1 \mathrm{KO}$ contains a deletion of the MAT1-1-1 gene in the $F$. graminearum strain Gz3639 background. It was created in Dr. John Leslie's laboratory (Kansas State University). This strain was kindly provided to us, with permission from Dr. Leslie, by Dr. Frances Trail (Michigan State University). Strain mat1-2-1KO is a MAT1-2-1 deletion mutant produced by splitmarker targeted gene deletion in the $\mathrm{PH}-1$ background (SB, unpublished). The parental strains were crossed by using the mycelial plug method (3). Five-millimeter plugs of mycelia taken from the edges of each parental strain, actively growing on PDA, were placed on opposite halves of a $60-\mathrm{mm}$ petri plate. After 4 days of incubation at $23^{\circ} \mathrm{C}$, perithecial production was induced by pipetting 500 to $1,000 \mu \mathrm{l}$ of $2.5 \%$ Tween 60 on the surface of each plate, and gently rubbing the aerial mycelium with a sterile glass rod to flatten it. Following induction, the plates were incubated at $23^{\circ} \mathrm{C}$ with constant fluorescent light until perithecial maturation. Two to three weeks after induction, the mature perithecia extruded cirrhi containing hundreds of ascospores. A sterile glass needle was used to pick up individual cirrhi, which were then dispersed in water and plated on $2 \%$ water agar. After growing on water agar for 10 to $14 \mathrm{~h}$, isolates arising from single ascospores were transferred to individual 6-mm petri plates. LOD scores were calculated using the MapMaker3 program (available for download from http://www.broadinstitute.org/scientific-community/ software).

FHB pathogenicity assay. The susceptible spring wheat variety "Norm" was used for the pathogenicity assays. Wheat seeds were planted in a mixture of topsoil (Maury silt loam) and PromixBX growth substrate (3:2) in cone containers and thinned after emergence to one seedling per cone. Plants were grown in the greenhouse with a 14/10-h photoperiod, provided by "Hortilux" LU430S/HTL/EN high pressure sodium lights, and ambient temperatures between 25 and $28^{\circ} \mathrm{C}$. Transplants were fertilized with 150 ppm of N:P:K (20:10:20) fertilizer formulation as needed, with the last fertilization at heading. Flowering typically occurred 6 to 7 weeks after planting. At earlyto mid-anthesis, a single centrally positioned floret on the primary flowering stem of each plant was inoculated with $10 \mu \mathrm{l}$ of a spore suspension as described previously (26). Symptom severity was recorded as the number of symptomatic spikelets per inoculated spike at 7 and 10 days post-inoculation.

\section{Results}

Species complex identification using MLGT analysis. Sixtyeight Fusarium isolates were recovered from mature heads of SRWW with symptoms of FHB from six production fields across the region (Table 2). MLGT analyses identified all of the isolates, with the exception of five from Owensboro (F-Ow-2, F-Ow-3, F-Ow-4, F-Ow-6, and F-Ow-7), as F. graminearum s.s. with the 15-ADON trichothecene genotype. The five Owensboro isolates were negative for all of the species and trichothecene genotype probes included in the MLGT assay, and were also negative for clade probes targeting all members of the FGSC and closely related species within the B-trichothecene-producing clade (B-clade) of Fusarium. These results indicated that the five Owensboro isolates were not members of the FGSC or the B-clade of Fusarium.

Identification of the Owensboro non-FGSC isolates. A portion of the translation elongation factor $1(E F-1 \alpha)$ gene was sequenced for each of the five Owensboro non-FGSC isolates and used to query FUSARIUM-ID, Fusarium MLST, and NCBI GenBank employing the BLASTn program. This revealed that all five isolates were members of the $F$. tricinctum species complex (FTSC). The sequences were subsequently analyzed phylogenetically after adding them to an in-house dataset for the FTSC. Three of the isolates (F-Ow-2, F-Ow-3, and F-Ow-4) were identified as $F$. acuminatum based on identical matches of the $E F-1 \alpha$ sequences to reference strains of this species (Fig. 1, Supplementary Table S1) that were isolated from Canadian wheat (GenBank accessions JX397863.1 and JX397866.1) (33), crown vetch (NRRL 13332 = FRC R-2109), pasture soil (NRRL $13406=$ FRC R-6638), pine nursery soil (NRRL $53951=$ CBS 119882), and a human bronchial secretion (NRRL $36147=$ CBS 109232, GenBank GQ5050420.1). The other two Owensboro strains (F-Ow-6 and F-Ow-7) were tentatively identified as $F$. cf. reticulatum based on a $100 \%$ match with $E F-1 \alpha$ sequences of strains

Table 2. Fungal isolates used in this study, and a summary of results

\begin{tabular}{|c|c|c|c|c|c|c|c|c|}
\hline $\begin{array}{l}\text { Location of } \\
\text { sample field }\end{array}$ & Field ID & $\begin{array}{l}\text { Symptomatic } \\
\text { wheat heads } \\
\text { collected }\end{array}$ & $\begin{array}{c}\text { Fusarium } \\
\text { graminearum } \\
\text { isolates } \\
\text { recovered }\end{array}$ & $\begin{array}{l}\text { Isolates of other } \\
\text { Fusarium spp. } \\
\text { recovered }\end{array}$ & $\begin{array}{c}\text { Unique telomere } \\
\text { profiles } \\
\text { among the } \\
F \text {. graminearum } \\
\text { isolates }\end{array}$ & $\begin{array}{c}\text { Wheat heads } \\
\text { with }>1 \\
\text { telomere } \\
\text { profile }^{\mathbf{a}}\end{array}$ & $\begin{array}{c}\text { Unique RFLP } \\
\text { profiles } \\
\text { among the } \\
F \text {. graminearum } \\
\text { isolates }\end{array}$ & $\begin{array}{c}\text { Wheat heads } \\
\text { with }>1 \text { RFLP } \\
\text { profile }\end{array}$ \\
\hline Hatfield, IN & F-IN & 5 & 12 & 0 & 7 & 3 & 9 & 3 \\
\hline Owensboro, $\mathrm{KY}$ & F-Ow & 4 & 2 & 5 & 1 & 2 & 2 & 0 \\
\hline Logan Co. KY & F-Lo & 4 & 8 & 0 & 2 & 0 & 3 & 0 \\
\hline Lexington, KY & F-Le & 6 & 18 & 0 & 13 & 5 & 14 & 6 \\
\hline Princeton, KY & F-Pr & 10 & 23 & 0 & 12 & 4 & 14 & 4 \\
\hline TOTAL & NA & 29 & 63 & 5 & 35 & 14 & 42 & 13 \\
\hline
\end{tabular}

a This column also includes the non- $F$. graminearum isolates. 
in the NCAUR database (Fig. 1) that were isolated from Danish soil (NRRL $25792=$ CBS 618.87) and passion fruit from New Zealand $($ NRRL $40040=$ ICMP 13864).

The FTSC strains did not produce FHB symptoms when inoculated onto heads of susceptible wheat plants. Florets inoculated with the five FTSC strains became brown and discolored, resembling a Type II (25) resistance response (Fig. $2 b$ and c). In contrast, the F. graminearum strain PH-1 (Fig. 2a), and the two strains from Owensboro that were identified as members of the FGSC (F-Ow-1, F-Ow-5) (not shown), produced significant bleaching typical of FHB.

FTSC strains produced macroconidia with morphologies that were distinct from that of $F$. graminearum s.s. (Fig. 2d). Macroconidia of the $F$. acuminatum strains (F-Ow-2, F-Ow-3, and F-Ow-4) were slightly more narrow and curved, with a distinct apical cell (Fig. $2 \mathrm{e}$ ). Macroconidia of the $F$. fc. reticulatum strains (F-Ow-6 and F-Ow-7) were significantly shorter, curved, and had a less distinct apical cell (Fig. 2f).

Comparative analyses of population structure and diversity using VNTR genotypes. Variable number tandem repeat (VNTR) data for the KY/IN FGSC population were combined with previously published data from the Upper Midwest (UMW), western Canada (WCAN), and Prince Edward Island (PEI) populations in order to assess their population structure and diversity in a broader geographic and genetic context. VNTR genotypes were determined for 62 of the $63 \mathrm{KY} / \mathrm{IN}$ FGSC isolates. The remaining isolate produced weak amplicons and was excluded from the VNTR analyses.

Analyses with STRUCTURE indicated that the four geographic populations fell into two major genetic clusters. Analyses with $K=$ 2 resulted in the greatest improvement in posterior probabilities ( $\Delta K=594.6$ ), whereas increasing values of $K$ produced much smaller improvements $(\Delta K \leq 48.3)$. Isolates were assigned to a specific genetic cluster when the estimate of membership $(Q)$ was $\geq 0.9$. With $K=2,95.4 \%$ of the isolates could be assigned to a specific genetic cluster, and these clusters were largely consistent with trichothecene genotype distinctions, as was previously observed in Canada and the Upper Midwest $(14,62)$. Among the isolates assigned to cluster 1, $94.3 \%$ were the 3 -ADON genotype, whereas $97.1 \%$ of the isolates assigned to cluster 2 had the 15-ADON genotype. All of the $\mathrm{KY} / \mathrm{IN}$ isolates had the 15-ADON trichothecene genotype, and 59 $(95.2 \%)$ of the $62 \mathrm{KY} / \mathrm{IN}$ isolates were assigned to cluster 2 . The three remaining unassigned isolates had $Q \geq 0.7$ for cluster 2 indicating that they are more similar to cluster 2 strains than to cluster 1 strains. No KY/IN isolates were assigned to cluster 1. Increasing the number of genetic clusters fragmented the population assignments for most of the 15 -ADON isolates from each of the four geographic populations, leaving more than half of the 15-ADON isolates unassigned to a genetic cluster, and further indicating that two genetic clusters captured the major genetic structure in these data.

The isolates were further divided into six groups based on their genetic cluster assignment and geographic origin in order to assess diversity and relatedness among these geographic/genetic populations (Table 3). As the genetic clusters largely corresponded to trichothecene genotype distinctions, these populations are referred to by geographic origin and their predominant trichothecene genotype. Neighbor-joining analyses based on $F_{S T}$ distances recovered two major clades associated with trichothecene genotype differences, with relationships and levels of genetic differentiation within each of these clades reflecting geographic separation (Fig. 3). Genetic differentiation between $\mathrm{KY} / \mathrm{IN}-15$ and the $15-\mathrm{ADON}$ populations from the Upper Midwest (UMW-15) and western Canada (WCAN-15) was relatively small $\left(F_{S T}=0.06\right.$ to 0.07$)$, but statistically significant $(P<0.001)$ and similar to the level of differentiation $\left(F_{S T}=0.03\right.$ to 0.06 ) between 3 -ADON populations in western Canada or the Upper Midwest (WCAN-3 and UMW-3) and the maritime province of Prince Edward Island (PEI-3). This indicates that the KY/IN-15 population is closely related to previously characterized $15-\mathrm{ADON}$ populations from NA, with a low level of genetic differentiation likely resulting from isolation by distance.
In comparison with the other geographic and genetic populations examined, intermediate levels of genetic diversity were observed within the KY/IN-15 population. The mean number of pairwise differences between haplotypes $(\pi=4.5)$, and average gene diversity over loci $(H=0.56)$, were slightly lower than was observed for the other $15-\mathrm{ADON}$ populations, but were substantially higher than in the 3-ADON populations (Table 3).

DNA fingerprinting using the telomere probe. Genomic DNA from each of the strains was restricted and probed with a telomerespecific probe (Fig. 4). The three $F$. acuminatum strains had identical telomere profiles consisting of eight bands, suggesting that they have at least four chromosomes. The two $F$. fc. reticulatum strains had more complex profiles that were similar to one another: F-Ow-07 had 14 bands, and F-Ow-06 had the same 14 bands plus one extra band, suggesting that these strains have seven or eight chromosomes. $F$. graminearum has four chromosomes, and thus we would expect to see eight bands hybridizing to the telomere probe. However, most of the strains had only two bands of varying sizes, probably due to the presence of doublets. At least 35 different telomere fingerprints were discerned among the strains, indicating a large amount of diversity. Patterns were sometimes shared among strains from the same

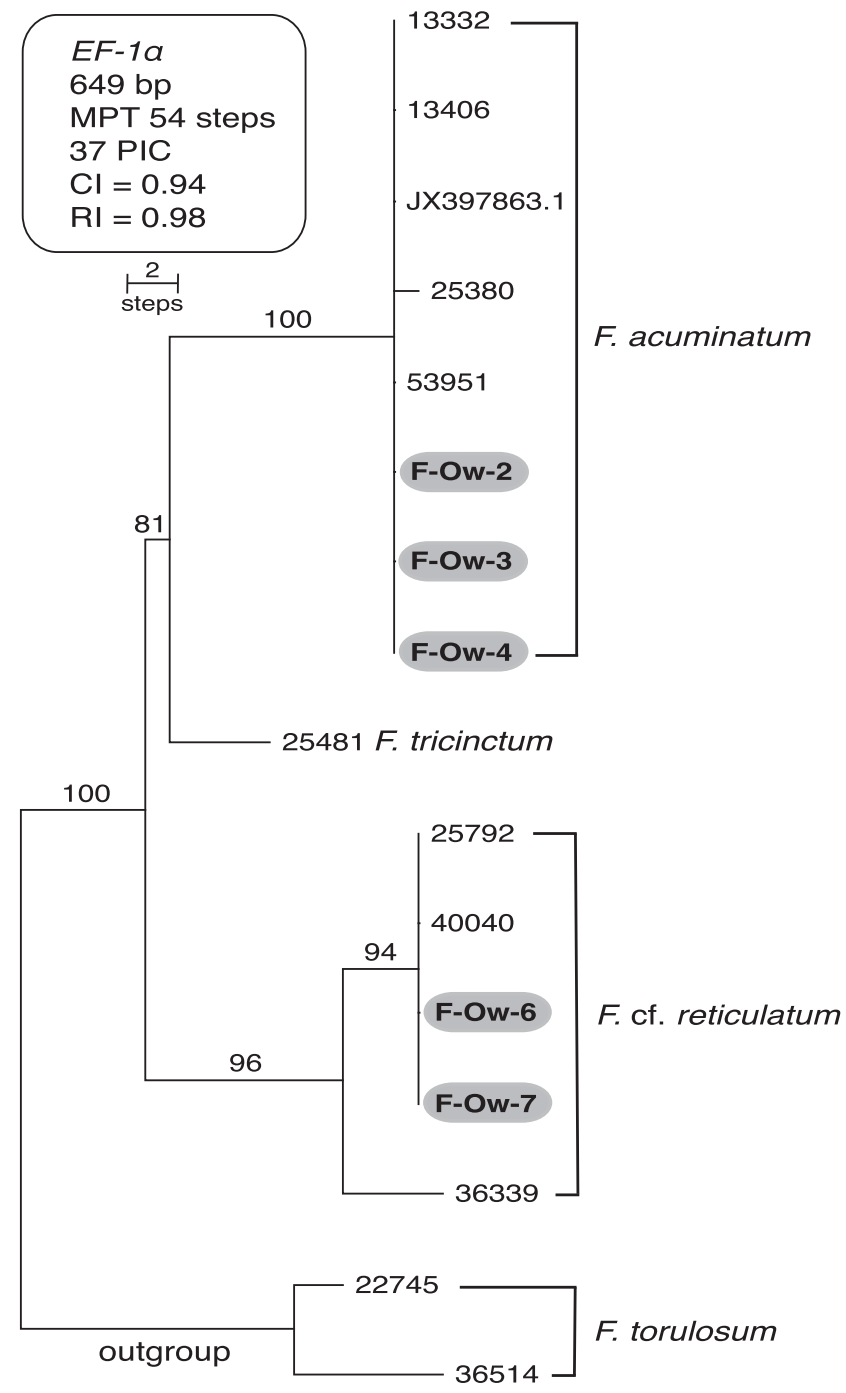

Fig. 1. Single most-parsimonious tree (MPT) inferred from 16 aligned partial translation elongation factor $(E F-1 \alpha)$ gene sequences rooted on outgroup sequences of Fusarium torulosum. Three of the five non- $F$. graminearum species complex isolates, which are indicated by gray highlight and bold font, were identified as $F$. acuminatum and the other two as $F$. cf. reticulatum. The number above nodes indicates MP bootstrap support based on 1,000 pseudoreplicates of the data. PIC, parsimony informative characters; $\mathrm{Cl}$, consistency index; $\mathrm{RI}$, retention index. 
locations, but were never shared among strains from different locations. The most diversity, consisting of 13 different hybridization patterns, was found among the 18 isolates collected in Lexington, KY (Table 2). In contrast, isolates from Logan County had relatively low levels of diversity, with only two patterns found among eight isolates (Table 2).

Repetitive fingerprinting probes. The repetitive probe Rep 1.92 hybridized to at least 24 polymorphic bands (Fig. 5), while the Rep1.52 probe hybridized to at least two polymorphic bands (Fig. 6). The five FTSC strains from Owensboro (F-Ow-02, F-Ow-03, F-Ow-04, F-Ow-06, and F-Ow-07) did not hybridize to either probe. The repetitive probes revealed genotypic diversity among the $F$. graminearum isolates, with unique RFLP fingerprints in each location ranging from $37.5 \%$ of the eight isolates from Logan County, to $100 \%$ (both) of the FGSC isolates from Owensboro (Table 2). In addition, multiple genotypes were often isolated from the same wheat head. The number of heads harboring multiple genotypes ranged from zero in the collections from Owensboro and Logan County, to six (100\% of the heads) from the Lexington location (Table 2). Three of the six heads from the Lexington collection contained three different genotypes, while the other three harbored two genotypes each. There were no isolates with identical RFLP fingerprints from different locations. Thus, every location appeared to have a unique set of RFLP genotypes. Although some strains with the same telomere banding pattern had different RFLP profiles, there were no strains that had the same RFLP profile that had different telomere banding patterns. Thus, the RFLP fingerprint data gives a better estimate of the actual number of different genotypes recovered from each location.

Each unique genotype was scored for presence or absence of the polymorphic bands, and the output was used to construct an unweighted pair group method with arithmetic mean (UPGMA) distance dendrogram (Fig. 7). Clustering was generally related to the origin of the genotypes. Two major groups, separated by an average distance of 0.98 , were resolved. The first group comprised the genotypes from the two fields in Princeton. The second group contained the F. graminearum strains from Owensboro; Hartfield, IN; Logan County; and Lexington. The FGSC F-Ow genotypes were located within a cluster that also contains the F-IN genotypes from just across the Ohio River.

Segregation of repetitive fingerprinting markers in FGSC. The repetitive probes hybridized to multiple polymorphic fragments within the FGSC population from Kentucky. A cross was made between a $\Delta$ mat1-1-1 strain (generated in the Gz3639 background) and a $\Delta$ mat1-2-1 strain (generated in the PH-1 background). It has been reported previously that deletion of complementary MAT genes in $F$. graminearum results in strains that are no longer homothallic, and can engage only in heterothallic matings (22).

Segregation of the CAPS markers and MAT1-1-1 and MAT1-2-1 genes was first evaluated to ensure that perithecia chosen for analysis resulted, as expected, from heterothallic crosses and showed normal segregation patterns. The CAPS markers and MAT genes each segregated in the expected $(1: 1)$ Mendelian ratios (Supplementary Figures $\mathrm{S} 1$ and $\mathrm{S} 2$ ).

Table 3. Diversity indices for the KY/IN-15 population in relation to five previously defined populations of Fusarium graminearum collected from wheat in North America

\begin{tabular}{lccc}
\hline Population & Isolates & $\boldsymbol{\Pi}^{\mathbf{a}}$ & $\boldsymbol{H}^{\mathbf{b}}$ \\
\hline KY/IN-15 & 59 & 4.5 & 0.56 \\
$\mathrm{UMW}^{\mathrm{c}} 5^{\mathrm{d}}$ & 24 & 5.0 & 0.62 \\
$\mathrm{WCAN}-15^{\mathrm{e}}$ & 53 & 4.9 & 0.61 \\
$\mathrm{UMW}^{\mathrm{f}}$ & 21 & 2.1 & 0.27 \\
WCAN-3g $^{\mathrm{g}}$ & 40 & 2.7 & 0.33 \\
PEI-3 & 22 & 3.1 & 0.39 \\
\hline
\end{tabular}

a Mean number of pairwise differences between haplotypes.

b Average gene diversity over loci.

${ }^{\mathrm{c}}$ Kentucky/Indiana 15-ADON population (this study).

${ }^{\mathrm{d}}$ Upper Midwest 15-ADON population (14,62).

e Western Canada 15-ADON population $(62)$.

${ }^{\mathrm{f}}$ Upper Midwest 3-ADON population $(14,62)$

$\mathrm{g}$ Western Canada 3-ADON population (62).

h Maritime province 3-ADON population (62).
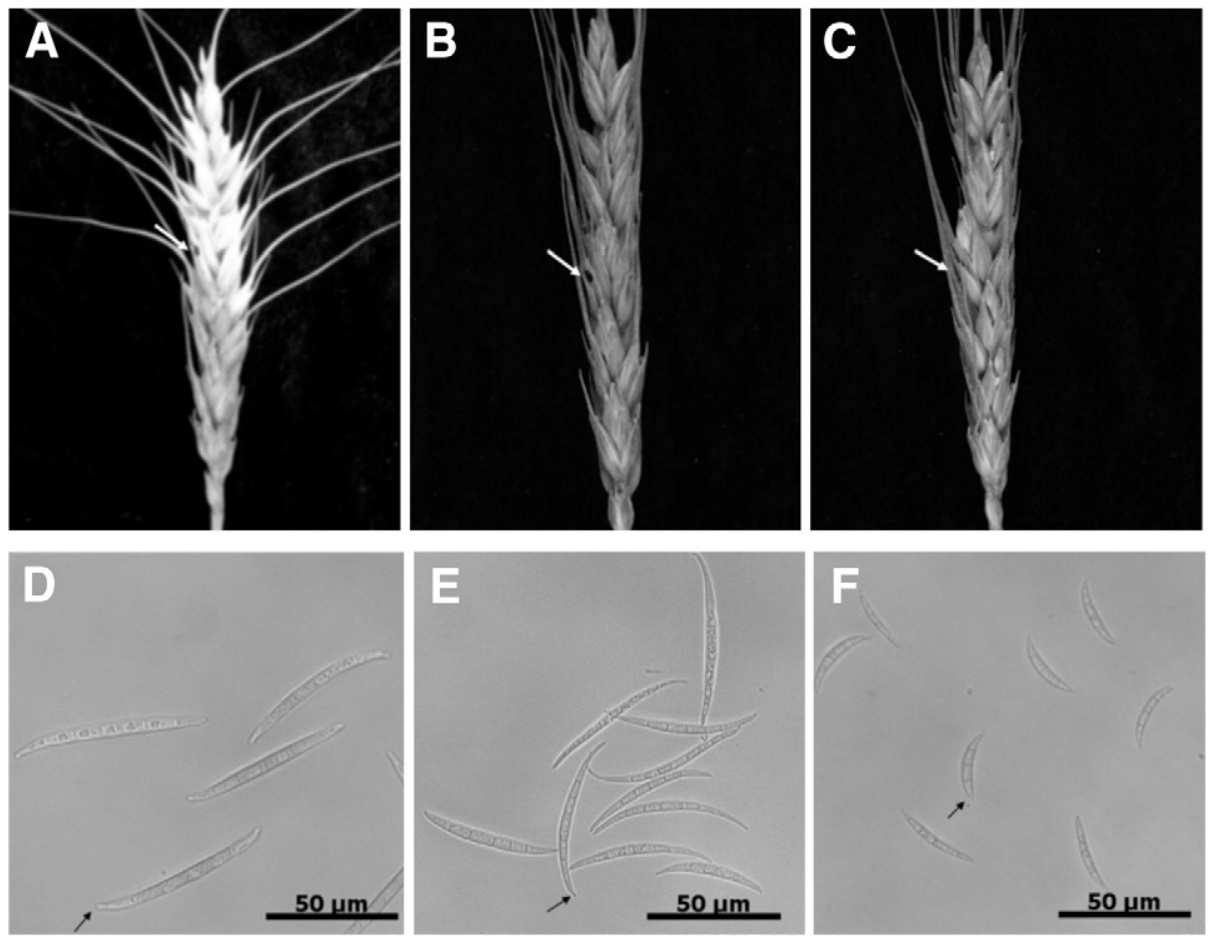

Fig. 2. Comparison of macroconidial morphology and agressiveness (7 dpi) of Fusarium graminearum strain PH-1 (A and D), with a representative $F$. acuminatum strain F-Ow-2 (B and $\mathbf{E}$ ) and a representative $F$. cf. reticulatum strain $\mathrm{F}-\mathrm{OW}-6$ ( $\mathbf{C}$ and $\mathbf{F})$. The point of inoculation on wheat heads in $A$ to $\mathrm{C}$ is indicated by the white arrows. Apical cells of individual macroconidia are indicated in $\mathrm{D}$ to $\mathrm{F}$ by black arrows. 
Four polymorphic bands that hybridized to the repetitive probe Rep1.92 in the two parental strains were scored as dominant markers, for presence or absence, among 20 progeny of the cross (Fig. 8). Statistical analysis of segregation patterns among the four markers using either $\chi^{2}$ or logarithm of odds (LOD) calculations suggested that they were all single unlinked loci (Table 4). It is important to point out that our sample size of only 20 progeny is relatively small: thus, if weak
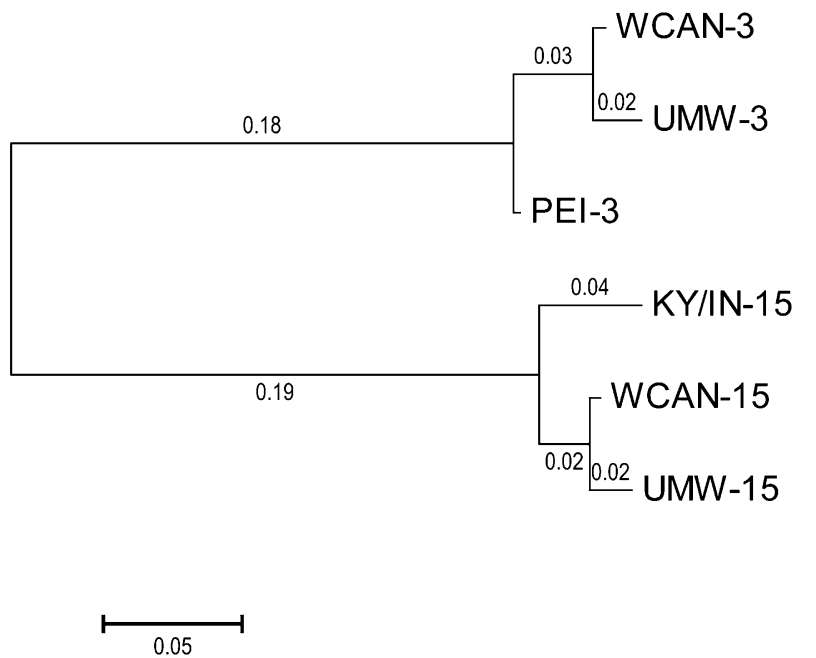

Fig. 3. Neighbor-joining phylogram based on $F_{S T}$ genetic distances derived from variable number tandem repeat (VNTR) analyses. Populations are referred to by geographic origin and their predominant trichothecene genotype. 3KY/IN-15= Kentucky/Indiana 15-ADON population (this study). UMW-15 = Upper Midwest 15ADON population $(14,62)$. WCAN-15 = Western Canada 15-ADON population (62). UMW-3 = Upper Midwest 3-ADON population (14,62). WCAN-3 = Western Canada 3-ADON population (62). PEI-3 = Maritime province 3-ADON population (62). linkage actually existed among any of these markers, we might not have been able to detect it. For marker Rep1.92-5, a 3:1 ratio fit the data with a higher significance for the $\chi^{2}$ calculation, which could imply that this band actually represents two unlinked loci, each of which produces a hybridizing fragment of a similar size. Use of this marker would be expected to result in the underestimation of actual population diversity. Markers Rep1.92-1 and Rep1.92-7 fit a 1:1 segregation model with a relatively low level of statistical confidence. However, a 3:1 model was even less likely for these markers.

\section{Discussion}

Genetic and phenotypic diversity in pathogen populations result from migration and gene flow, sexual recombination, and mutation. Selective forces, including host factors such as resistance, act on this diversity to drive shifts in the pathogen population (4). The ability to track diversity in a pathogen population is an important aid to understanding and predicting the role of selective forces in the development of disease epidemics.

A vast majority of Fusarium strains causing FHB in North America are members of $F$. graminearum Schwabe (36). The prevalent chemotype is $15-\mathrm{ADON}(14,27,62)$, which dominates worldwide on wheat in temperate zones (59). Recently, an increase in the representation of 3-ADON isolates in the population has been documented in Canada (11,17,61), the upper Midwestern United States (14), and the eastern United States, from North Carolina to New York $(25,47,48)$. It has been reported that these 3-ADON isolates represent a novel and likely introduced population. Moreover, strains from this new population produce higher levels of trichothecenes, grow faster in vitro, have higher fecundity, produce larger macroconidia, are more aggressive $(5,12,15,40,58,62)$, and are more resilient under extreme environmental conditions, suggesting that $F$. graminearum is undergoing an adaptive evolutionary shift in North America $(14,62)$. Although the same studies demonstrated that sexual recombination had occurred between the 3 -ADON population and the dominant 15-ADON

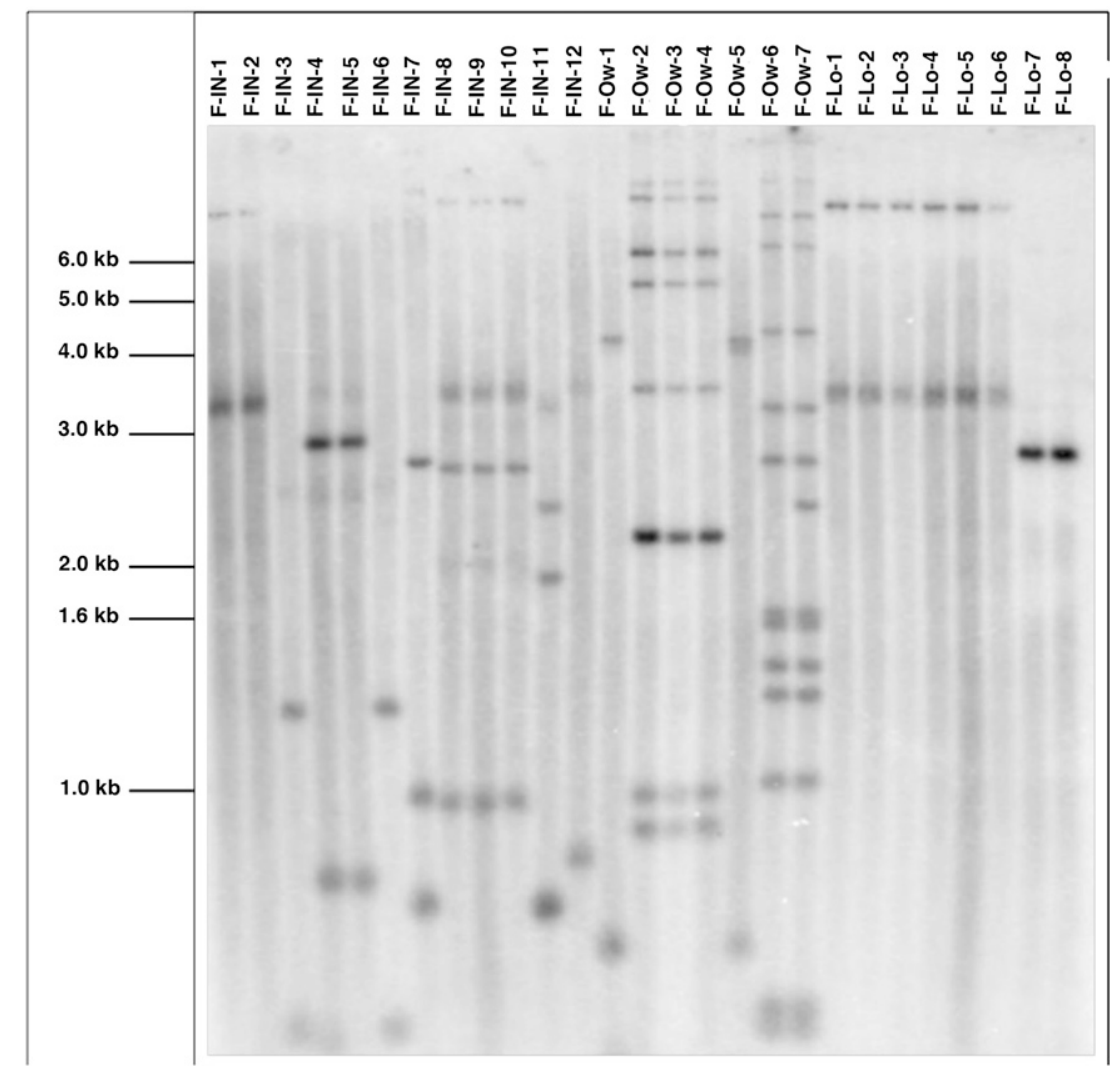

Fig. 4. An example of a Southern blot analysis of the BsoBI digest of fungal isolates from Hartfield, IN (F-IN); Owensboro, KY (F-Ow); and Logan Co., KY (F-Lo). The digest was probed with a (TTAGGG)n telomere specific probe. 


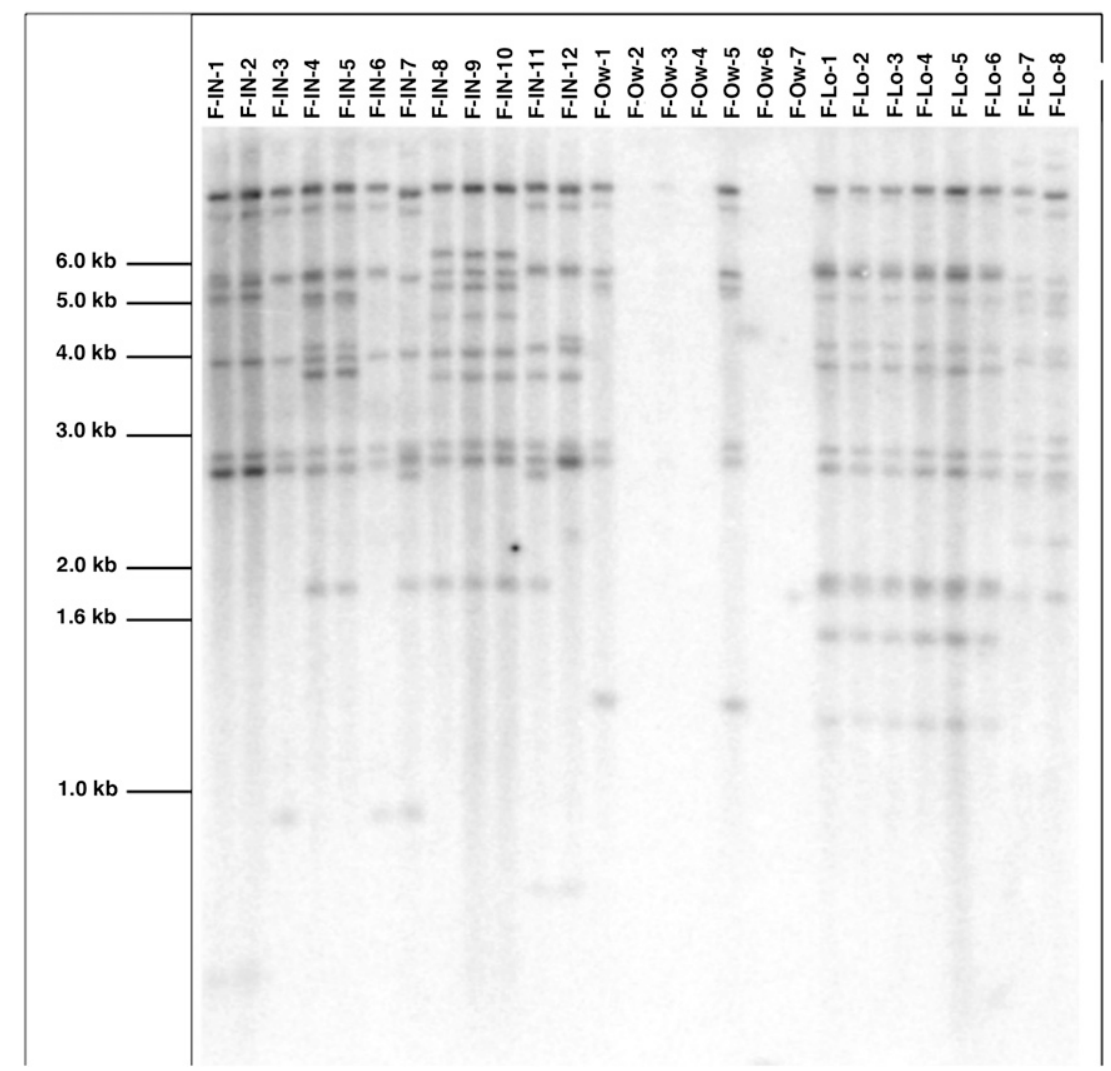

Fig. 5. Example of Southern blot analysis of the BsoBI digest of the sets of fungal isolates from Hartfield, IN (F-IN); Owensboro, KY (F-Ow); and Logan Co., KY (F-Lo) probed with restriction fragment length polymorphism (RFLP) probe Rep1.92.

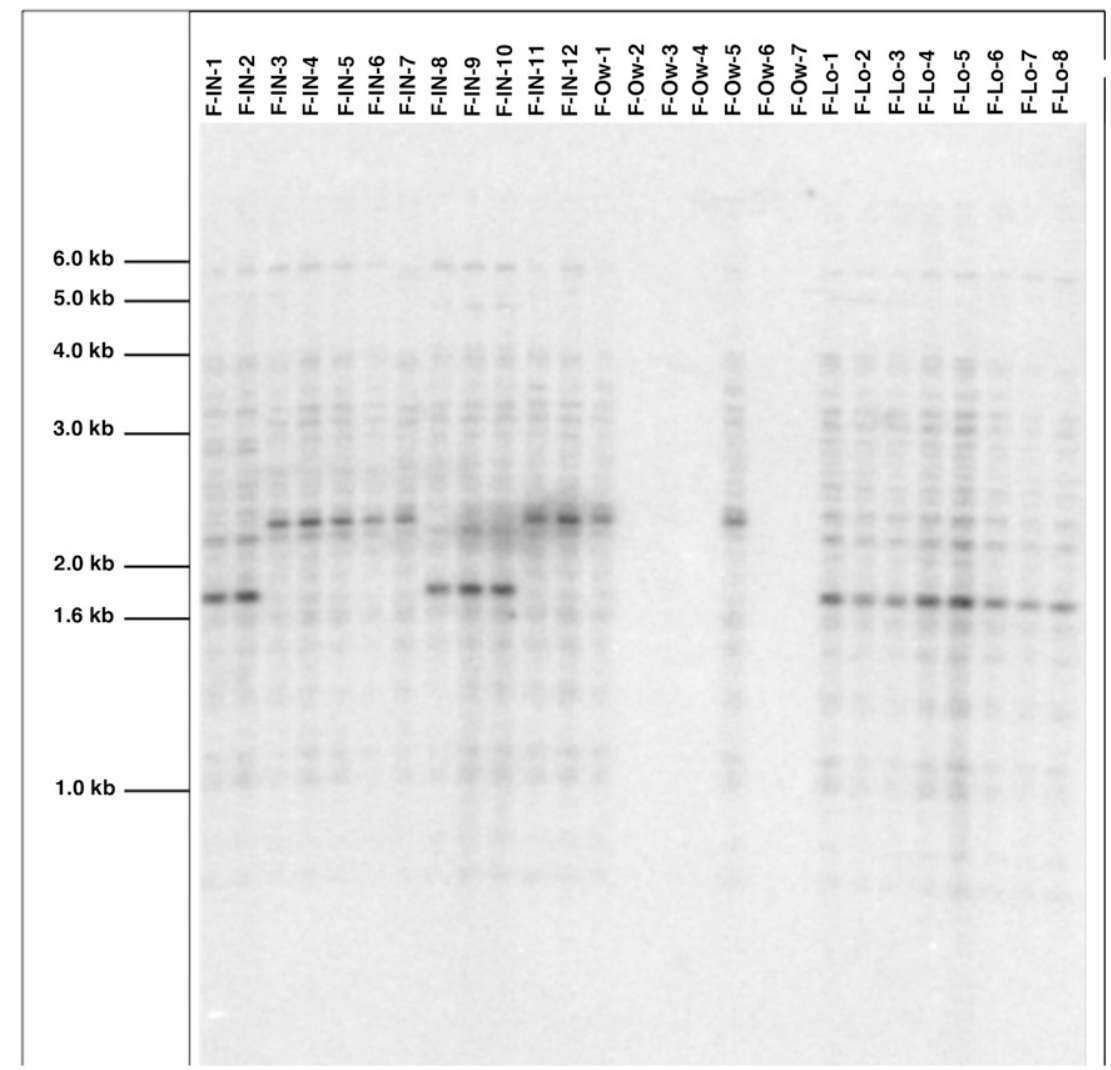

Fig. 6. Example of Southern blot analysis of the BsoBI digest of the sets of fungal isolates from Hartfield, IN (F-IN); Owensboro, KY (F-Ow); and Logan Co., KY (F-Lo) probed with restriction fragment length polymorphism (RFLP) probe Rep1.52. 
population, admixture thus far has been insufficient to homogenize the two populations. Spolti et al. (51) reported no differences in several measures of pathogenic and saprophytic fitness between 3-ADON and 15-ADON isolates from New York, but these analyses were not accompanied by genetic analyses of population assignment. A shift in pathogen populations and chemotype frequencies has been observed among $F$. asiaticum affecting wheat in China, where a less aggressive NIV chemotype is being replaced by a more aggressive and more toxigenic 3-ADON chemotype population (68).

NIV-producing subpopulations of $F$. graminearum have been found in Korea (21), China $(30,41)$, Nepal $(8,9)$, New Zealand (28), Argentina $(42,43)$, and Italy $(38,39)$. NIV-producing $F$. graminearum strains are most prevalent on rice and corn in Korea $(20,23)$, and on corn in Nepal (9) and Argentina (42,43). In the United States, the NIV chemotype appears to be common only in southern Louisiana, where $79 \%$ of the $F$. graminearum isolates from wheat were NIV producers (13). A smaller proportion of Louisiana $F$. graminearum isolates belonged to the 3-ADON chemotype. Very small numbers of NIV strains have been found in other states including Arkansas, Missouri, North Carolina, New York, and North Dakota. It has been suggested that NIV strains may be particularly well adapted to rice agroecosystems, which are common in southern Louisiana $(13,36,52)$.

Kentucky represents a transition zone between the Mid-Atlantic, Midwestern, and Gulf Coast wheat production areas, so there is potential for introduction and subsequent hybridization among $F$. graminearum genotypes adapted to the surrounding wheat- and corn (Zea mays)-producing regions. Population genetic tools can be used to monitor and detect these events. The $F$. graminearum isolates causing FHB in Kentucky all belonged to the most prevalent North American population of $15-A D O N F$. graminearum. Predominance of the 15-ADON trichothecene genotype in Kentucky is consistent with the findings of an earlier study (48), although one 3-ADON isolate was identified in that study, from Logan County. Additional sampling incorporating strains recovered from additional hosts is needed before we can make firm conclusions about the chemotype diversity (or lack thereof) among the FGSC in Kentucky.

Although the Kentucky population appears to belong to the dominant NA population, a small but significant level of population differentiation was identified between the 15-ADON populations in Kentucky and those of the Upper Midwest and Canada, consistent with isolation by distance. The present study also revealed genetic diversity among the isolates examined. A telomere probe revealed at least 35 different genotypes among the 68 strains in the study. We took advantage of the published sequence of $F$. graminearum (7) to develop some new markers for genetic analysis. By comparing the $\mathrm{PH}-1$ genome sequence against itself, we generated a list of highly repetitive sequences ( $>20$ copies) that had potential as fingerprinting probes. The repetitive fingerprinting probes revealed even more genetic diversity among the isolates in our study: 65 FGSC isolates could be classified into 45 different genotypes with these markers. None of the isolates had fingerprints that were identical to PH-1 from Michigan and Gz3639 from Kansas. A high degree of diversity among patterns of other neutral markers has been reported for other F. graminearum populations in North America $(13,14,16$, $46,66,67)$. In the current study, isolates from the same location were more similar than isolates from different locations, and isolates with the same pattern were not recovered from more than one location, suggesting that short-distance movement dominates over long-

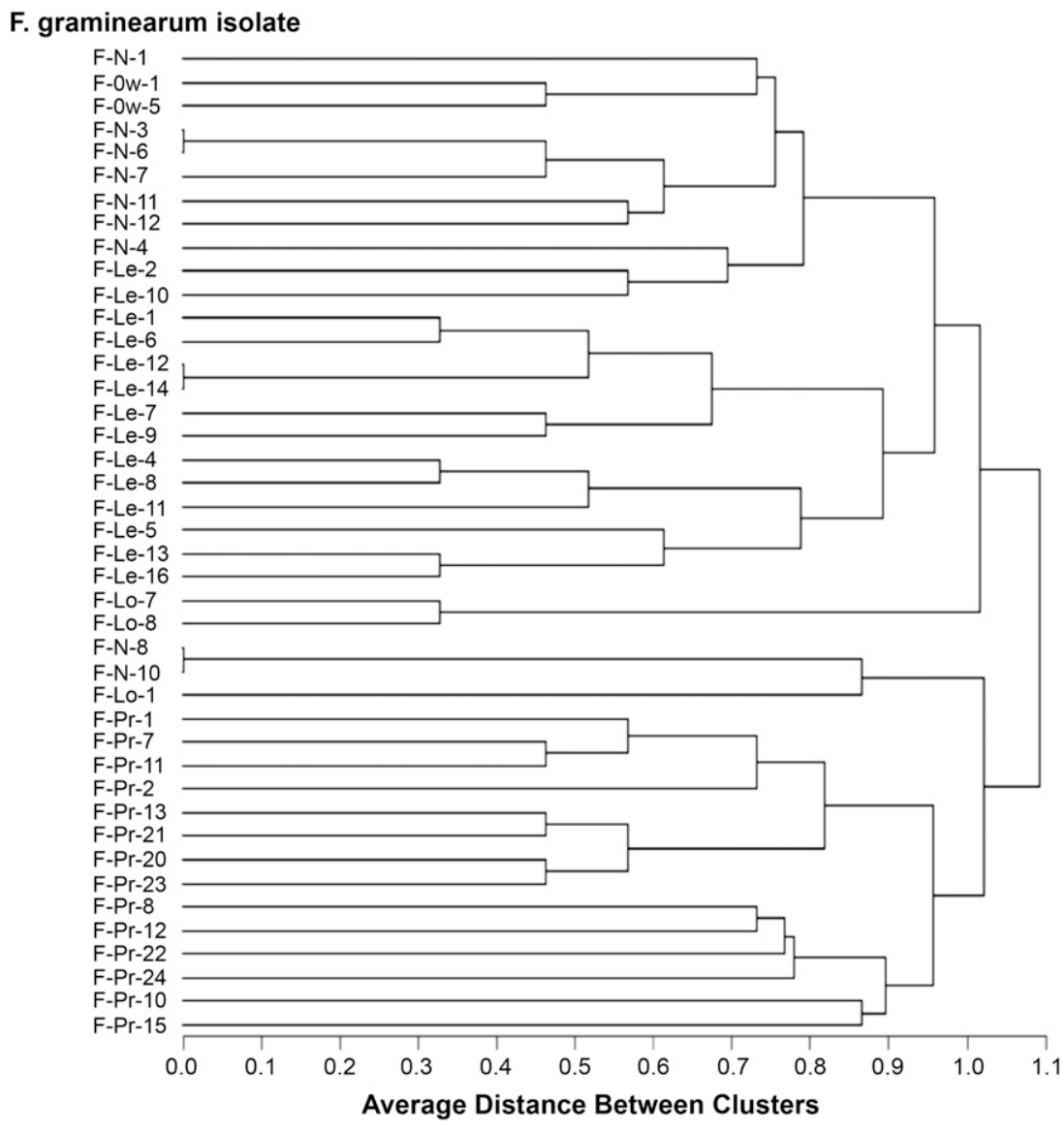

Fig. 7. Unweighted pair group method with arithmetic average (UPGMA) "dendrogram" of Fusarium graminearum genotypes representing isolates collected across Kentucky and Indiana. The samples were collected from one field in Lexington KY [F-Le]; two fields in Princeton, KY [F-Pr]; one field in Owensboro, KY [F-Ow]; one field in Logan Co., KY [F-Lo]; and one field in Hartfield, IN [F-IN]. The UPGMA dendrogram was constructed based on the Jaccard similarity matrix among RFLP profiles from BsoBI DNA digests probed with RFLP probe Rep1.92. The scale bar indicates Jaccard similarity values. 
distance migration. A similar relationship between genetic distance and geographic distance has also been reported previously $(46,66)$. We recovered an average of $2.07( \pm 0.82)$ genotypes from each blighted wheat head, which is comparable with the average of 1.8 genotypes/head reported in another study (66). Additional sampling will be needed to draw broader conclusions about potential variation in FGSC diversity across the state. In the future, these and additional fingerprinting markers can be used to compare populations in Kentucky with those in other states, and to monitor the occurrence, evolution, and spread of populations and individual clones within the state.

Among the Fusarium strains isolated from samples collected from the fields in Owensboro, KY, there were several representing species other than $F$. graminearum. F. acuminatum has a broad host range, and is known as a causal agent of FHB on barley (64). On wheat it is more common as a root and crown rot pathogen (53), although it was recently reported to cause FHB in northern China (60). This species is reported to produce enniatins, moniliformin, and T-2 toxin (24). F. reticulatum was found associated with seeds of Medicago littoralis and M. truncatula $(19,56)$, wheat and barley roots (53), and causing necrosis in English oak (Quercus robur) (29) and red staining in box elder (Acer negundo) (2). These strains were tested for pathogenicity on the susceptible spring wheat variety 'Norm,' but they did not produce disease symptoms under greenhouse conditions. The strains initially came from a severely symptomatic SRWW heads, so the lack of aggressiveness observed under greenhouse conditions could mean that host or environmental factors were not optimal for pathogenicity of these isolates. Alternatively, these isolates may have been present in combination with a pathogenic $F$. graminearum strain that was actually responsible for the disease symptoms.

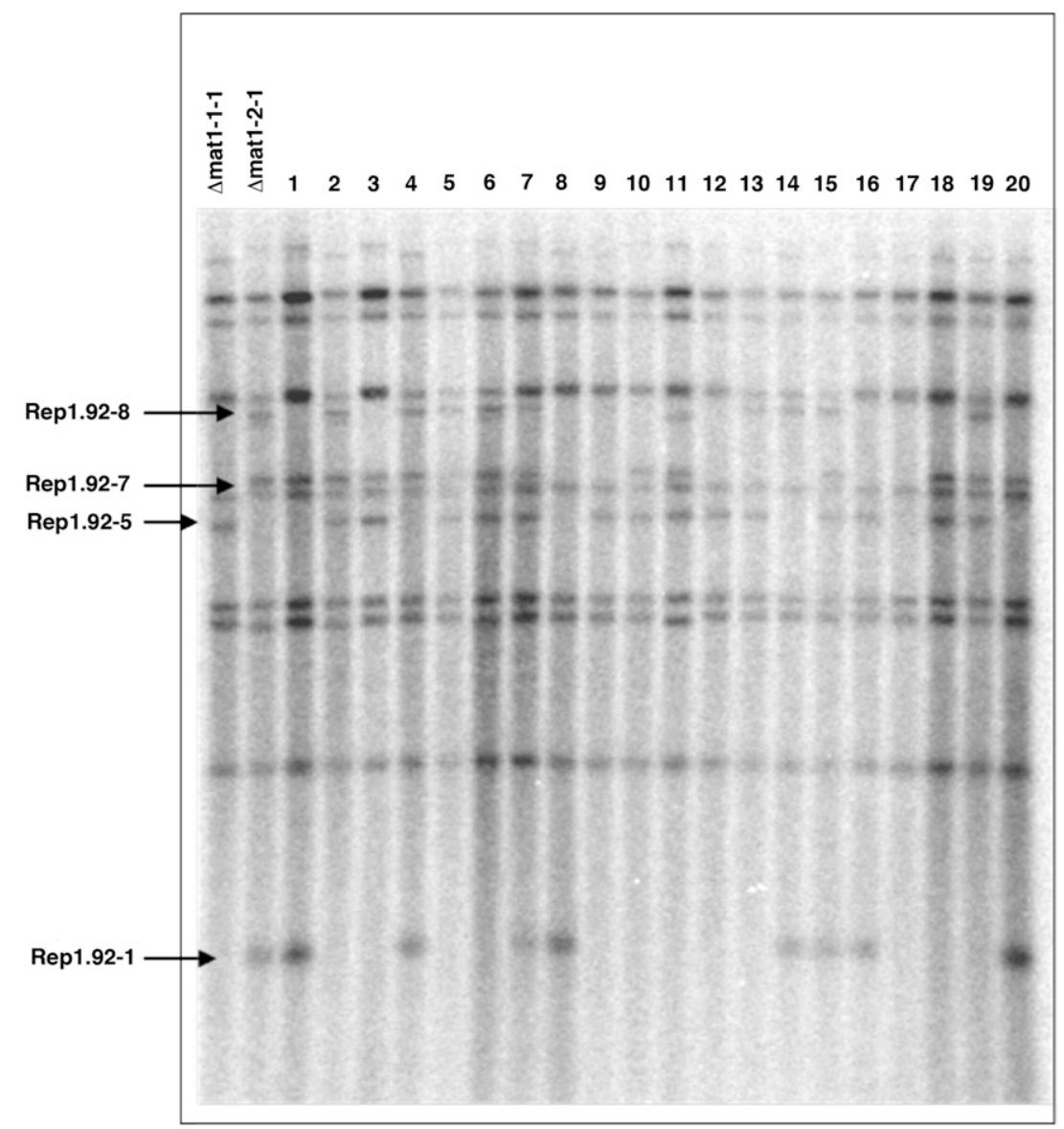

Fig. 8. Example of the use of Rep1.92 probe to detect recombination among polymorphic restriction fragment length polymorphism (RFLP) markers in 20 progeny of a cross between $\Delta$ mat1-1-1 (Gz3639) and $\Delta$ mat1-2-1(PH-1). Bands that are polymorphic between the two parent strains are indicated by the arrows.

Table 4. Segregation analyses for the repetitive RFLP molecular markers among F1 progeny from a cross between $\Delta$ mat1-1-1 (Gz3639) and $\Delta$ mat1-2-1(PH-1)

\begin{tabular}{|c|c|c|c|c|c|c|c|}
\hline Single marker & Expected & Observed & Df & Critical value $(P=0.05)$ & $\chi^{2}$ & $\mathbf{P}$ & LOD score \\
\hline Rep1.92-1 & $10: 10$ & $8: 12$ & 1 & 3.8 & 0.8 & 0.37 & NA \\
\hline Rep1.92-5 & 10:10 (1 locus) & $14: 6$ & 1 & 3.8 & 3.2 & 0.07 & NA \\
\hline Rep1.92-5 & $15: 5$ (2 loci) & $14: 6$ & 1 & 3.8 & 0.3 & 0.61 & NA \\
\hline Rep1.92-7 & $10: 10$ & $12: 8$ & 1 & 3.8 & 0.8 & 0.37 & NA \\
\hline Rep1.92-8 & $10: 10$ & $9: 11$ & 1 & 3.8 & 0.2 & 0.66 & NA \\
\hline Marker pairs & Expected & Observed & Df & Critical value $(P=0.05)$ & $x^{2}$ & $\mathbf{P}$ & LOD score \\
\hline $\begin{array}{l}\text { Rep1.92-1 } \\
\text { Rep1.92-7 }\end{array}$ & $5: 5: 5: 5$ & $5: 3: 7: 5$ & 3 & 7.8 & 1.6 & 0.66 & 0.02 \\
\hline $\begin{array}{l}\text { Rep1.92-1 } \\
\text { Rep1.92-8 }\end{array}$ & $5: 5: 5: 5$ & $4: 4: 5: 7$ & 3 & 7.8 & 1.2 & 0.75 & 0.58 \\
\hline $\begin{array}{l}\text { Rep1.92-7 } \\
\text { Rep1.92-8 }\end{array}$ & $5: 5: 5: 5$ & $6: 6: 3: 5$ & 3 & 7.8 & 1.2 & 0.75 & 0 \\
\hline
\end{tabular}


Our findings provide an important baseline for future monitoring of population dynamics among FGSC strains causing FHB in Kentucky. A detailed understanding of the population structure, and timely detection of shifts in that population, will be valuable for breeding programs focused on developing wheat varieties with a broad and durable resistance to the targeted pathogen population.

\section{Acknowledgments}

We thank Etta M. Nuckles, Doug J. Brown, Thomas Usgaard, and Nathane Orwig for excellent technical assistance. The mention of firm names or trade products does not imply that they are endorsed or recommended by the US Department of Agriculture over other firms or similar products not mentioned. The USDA is an equal opportunity provider and employer. This is paper number 14-12-083 from the University of Kentucky Agriculture Experiment Station, published with the permission of the Director. Financial support for this research was generously provided by the U.S. Wheat and Barley Scab Initiative.

\section{Literature Cited}

1. Bai, G. H., and Shaner, G. 1996. Variation in Fusarium graminearum and cultivar resistance to wheat scab. Plant Dis. 80:975-979.

2. Batra, L. R., and Lichtwardt, R. W. 1962. Red stain of Acer negundo. Mycologia 54:91-97.

3. Bowden, R. L., and Leslie, J. F. 1999. Sexual recombination in Gibberella zeae. Phytopathology 89:182-188.

4. Burdon, J. J., and Silk, J. 1997. Sources and patterns of diversity in plantpathogenic fungi. Phytopathology 87:664-669.

5. Burlakoti, R. R., Neate, S. M., Adhikari, T. B., Gyawali, S., Salas, B., Steffenson, B. J., and Schwarz, P. B. 2011. Trichothecene profiling and population genetic analysis of Gibberella zeae from barley in North Dakota and Minnesota. Phytopathology 101:687-695.

6. Cowger C., and Sutton, A. L. 2005. The southeastern U.S. Fusarium head blight epidemic of 2003. Plant Health Progress Online publication doi: 10.1094/PHP-2005-1026-01-RS.

7. Cuomo, C. A., Güldener, U., Xu, J.-R., Trail, F., Turgeon, B. G., Di Pietro, A., Walton, J. D., Ma, L.-J., Baker, S. E., Rep, M., Adam, G., Antoniw, J., Baldwin, T., Calvo, S., Chang, Y.-L., Decaprio, D., Gale, L. R., Gnerre, S., Goswami, R. S., Hammond-Kosack, K., Harris, L. J., Hilburn, K., Kennell, J. C., Kroken, S., Magnuson, J. K., Mannhaupt, G., Mauceli, E., Mewes, H.-W., Mitterbauer, R., Muehlbauer, G., Münsterkötter, M., Nelson, D., O'Donnell, K., Ouellet, T., Qi, W., Quesneville, H., Roncero, M. I. G., Seong, K.-Y., Tetko, I. V., Urban, M., Waalwijk, C., Ward, T. J., Yao, J., Birren, B. W., and Kistler, H. C. 2007. The Fusarium graminearum genome reveals a link between localized polymorphism and pathogen specialization. Science 317:1400-1402.

8. Desjardins, A. E., Manandhar, H. K., Plattner, R. D., Manandhar, G. G., Poling, S. M., and Maragos, C. M. 2000. Fusarium species from nepalese rice and production of mycotoxins and gibberellic acid by selected species. Appl. Environ. Microbiol. 66:1020-1025.

9. Desjardins, A. E., and Proctor, R. H. 2011. Genetic diversity and trichothecene chemotypes of the Fusarium graminearum clade isolated from maize in Nepal and identification of a putative new lineage. Fungal Biol. 115:38-48.

10. Excoffier, L., and Lischer, H. E. L. 2010. Arlequin suite ver 3.5: A new series of programs to perform population genetics analyses under Linux and Windows. Mol. Ecol. Resour. 10:564-567.

11. Fernando, W. G. D., Zhang, J. X., Dusabenyagasani, M., Guo, X. W., Ahmed, H., and McCallum, B. D. 2006. Genetic diversity of Gibberella zeae isolates from Manitoba. Plant Dis. 90:1337-1342.

12. Foroud, N. A., McCormick, S. P., MacMillan, T., Badea, A., Kendra, D. F., Ellis, B. E., and Eudes, F. 2012. Greenhouse studies reveal increased aggressiveness of emergent Canadian Fusarium graminearum chemotypes in wheat. Plant Dis. 96:1271-1279.

13. Gale, L. R., Harrison, S. A., Ward, T. J., O’Donnell, K., Milus, E. A., Gale, S. W., and Kistler, H. C. 2011. Nivalenol-type populations of Fusarium graminearum and $F$. asiaticum are prevalent on wheat in southern Louisiana. Phytopathology 101:124-134.

14. Gale, L. R., Ward, T. J., Balmas, V., and Kistler, H. C. 2007. Population subdivision of Fusarium graminearum sensu stricto in the Upper Midwestern United States. Phytopathology 97:1434-1439.

15. Gilbert, J., Clear, R. M., Ward, T. J., Gaba, D., Tekauz, A., Turkington, T. K., Woods, S. M., Nowicki, T., and O'Donnell, K. 2010. Relative aggressiveness and production of 3- or 15-acetyl deoxynivalenol and deoxynivalenol in spring wheat. Can. J. Plant Pathol. 32:146-152.

16. Goswami, R. S., and Kistler, H. C. 2004. Heading for disaster: Fusarium graminearum on cereal crops. Mol. Plant Pathol. 5:515-525.

17. Guo, X. W., Fernando, W. G. D., and Seow-Brock, H. Y. 2008. Population structure, chemotype diversity, and potential chemotype shifting of Fusarium graminearum in wheat fields of Manitoba. Plant Dis. 92:756-762.

18. Königs, M., Schwerdt, G., Gekle, M., and Humpf, H.-U. 2008. Effects of the mycotoxin deoxynivalenol on human primary hepatocytes. Mol. Nutr. Food Res. 52:830-839.
19. Lamprecht, S. C., Marasas, W. F. O., Thiel, P. G., Schneider, D. J., and KnoxDavies, P. S. 1986. Incidence and toxigenicity of seedborne Fusarium species from annual Medicago species in South Africa. Phytopathology 76: 1040-1042.

20. Lee, J., Chang, I. Y., Kim, H., Yun, S. H., Leslie, J. F., and Lee, Y. W. 2009 Genetic diversity and fitness of Fusarium graminearum populations from rice in Korea. Appl. Environ. Microbiol. 75:3289-3295.

21. Lee, J., Kim, H., Jeon, J. J., Kim, H. S., Zeller, K. A., Carter, L. L. A., Leslie, J. F., and Lee, Y. W. 2012. Population structure and mycotoxin production by Fusarium graminearum from maize in South Korea. Appl. Environ. Microbiol. 78:2161-2167.

22. Lee, J., Lee, T., Lee, Y.-W., Yun, S.-H., and Turgeon, B. G. 2003. Shifting fungal reproductive mode by manipulation of mating type genes: obligatory heterothallism of Gibberella zeae. Mol. Microbiol. 50:145-152.

23. Lee, S. H., Lee, J., Nam, Y. J., Lee, S., Ryu, J. G., and Lee, T. 2010. Population structure of Fusarium graminearum from maize and rice in 2009 in Korea. Plant Pathol. J. 26:321-327.

24. Logrieco, A., Altomare, C., Moretti, A., and Bottalico, A. 1992. Cultural and toxigenic variability in Fusarium acuminatum. Mycol. Res. 96:518-523.

25. McMullen, M., Bergstrom, G., De Wolf, E., Dill-Macky, R., Hershman, D., Shaner, G., and Van Sanford, D. 2012. A unified effort to fight an enemy of wheat and barley: Fusarium head blight. Plant Dis. 96:1712-1728.

26. Miedaner, T., Moldovan, M., and Ittu, M. 2003. Comparison of spray and point inoculation to assess resistance to Fusarium head blight in a multienvironment wheat trial. Phytopathology 93:1068-1072.

27. Miller, J. D., and Greenhalgh, R. 1991. Trichothecene chemotypes of three Fusarium species. Mycologia 83:121-130.

28. Monds, R. D., Cromey, M. G., Lauren, D. R., di Menna, M., and Marshall, J. 2005. Fusarium graminearum, F. cortaderiae and $F$. pseudograminearum in New Zealand: molecular phylogenetic analysis, mycotoxin chemotypes and co-existence of species. Mycol. Res. 109:410-420.

29. Montecchio, L., and Accordi, S. M. 2007. Endophytic occurrence of a pathogenic strain of Fusarium reticulatum in English oak in Italy. J. Plant Pathol. 89:S74.

30. Ndoye, M., Zhang, J. B., Wang, J. H., Gong, A. D., Li, H. P., Qu, B., Li, S. J., and Liao, Y. C. 2012. Nivalenol and 15-acetyldeoxynivalenol chemotypes of Fusarium graminearum clade species are prevalent on maize throughout China. J. Phytopathol. 160:519-524.

31. Nganje, W. 2003. Economic impact of Fusarium head blight in malting barley: blending margins and firm-level risk. Curr. Agr. Food Resour. Iss. 4:16-26.

32. Nganje, W. E., Bangsund, D. A., Leistritz, F. L., Wilson, W. W., and Tiapo, N. M. 2004. Regional economic impacts of Fusarium head blight in wheat and barley. Appl. Econ. Perspect. Pol. 26:332-347.

33. Niessen, L., Grafenham, T., and Vogel, R. F. 2012. ATP citrate lyase 1 (acll) gene-based loop-mediated amplification assay for the detection of the Fusarium tricinctum species complex in pure cultures and in cereal samples. Int. J. Food Microbiol. 158:171-185.

34. O’Donnell, K., Kistler, H. C., Tacke, B. K., and Casper, H. H. 2000. Gene genealogies reveal global phylogeographic structure and reproductive isolation among lineages of Fusarium graminearum, the fungus causing wheat scab. Proc. Natl. Acad. Sci. USA 97:7905-7910.

35. O'Donnell, K., Ward, T. J., Aberra, D., Kistler, H. C., Aoki, T., Orwig, N., Kimura, M., Bjørnstad, S., and Klemsdal, S. S. 2008. Multilocus genotyping and molecular phylogenetics resolve a novel head bligh pathogen within the Fusarium graminearum species complex from Ethiopia. Fungal Genet. Biol. 45:1514-1522.

36. O'Donnell, K., Ward, T. J., Geiser, D. M., Corby Kistler, H., and Aoki, T 2004. Genealogical concordance between the mating type locus and seven other nuclear genes supports formal recognition of nine phylogenetically distinct species within the Fusarium graminearum clade. Fungal Genet. Biol. 41:600-623.

37. Pritchard, J. K., Stephens, M., and Donnelly, P. 2000. Inference of population structure using multilocus genotype data. Genetics 155:945-959.

38. Prodi, A., Purahong, W., Tonti, S., Salomoni, D., Nipoti, P., Covarelli, L., and Pisi, A. 2011. Difference in chemotype composition of Fusarium graminearum populations isolated from durum wheat in adjacent areas separated by the Apennines in Northern-Central Italy. Plant Pathol. J. 27:354-359.

39. Prodi, A., Tonti, S., Nipoti, P., Pancaldi, D., and Pisi, A. 2009. Identification of deoxynivalenol and nivalenol producing chemotypes of Fusarium graminearum isolates from durum wheat in a restricted area of northern Italy. J. Plant Pathol. 91:727-731

40. Puri, K. D., and Zhong, S. 2010. The 3ADON population of Fusarium graminearum found in North Dakota is more aggressive and produces a higher level of DON than the prevalent 15ADON population in spring wheat. Phytopathology 100:1007-1014.

41. Qu, B., Li, H. P., Zhang, J. B., Xu, Y. B., Huang, T., Wu, A. B., Zhao, C. S., Carter, J., Nicholson, P., and Liao, Y. C. 2008. Geographic distribution and genetic diversity of Fusarium graminearum and $F$. asiaticum on wheat spikes throughout China. Plant Pathol. 57:15-24.

42. Sampietro, D. A., Díaz, C. G., Gonzalez, V., Vattuone, M. A., Ploper, L. D., Catalan, C. A. N., and Ward, T. J. 2011. Species diversity and toxigenic potential of Fusarium graminearum complex isolates from maize fields in northwest Argentina. Int. J. Food Microbiol. 145:359-364. 
43. Sampietro, D. A., Ficoseco, M. E., Jimenez, C. M., Vattuone, M. A., and Catalan, C. A. 2012. Trichothecene genotypes and chemotypes in Fusarium graminearum complex strains isolated from maize fields of northwest Argentina. Int. J. Food Microbiol. 153:229-233.

44. Sarver, B. A. J., Ward, T. J., Gale, L. R., Broz, K., Kistler, H. C., Aoki, T., Nicholson, P., Carter, J., and O'Donnell, K. 2011. Novel Fusarium head blight pathogens from Nepal and Louisiana revealed by multilocus genealogical concordance. Fungal Genet. Biol. 48:1096-1107.

45. Schechtman, M. G. 1990. Characterization of telomere DNA from Neurospora crassa. Gene 88:159-165.

46. Schmale, D. G., Leslie, J. F., Zeller, K. A., Saleh, A. A., Shields, E. J., and Bergstrom, G. C. 2006. Genetic structure of atmospheric populations of Gibberella zeae. Phytopathology 96:1021-1026.

47. Schmale, D. G., Ross, S. D., Fetters, T. L., Tallapragada, P., Wood-Jones, A. K., and Dingus, B. 2012. Isolates of Fusarium graminearum collected 40-320 meters above ground level cause Fusarium head blight in wheat and produce trichothecene mycotoxins. Aerobiologia Online publication doi: 10.1007/s10453-011-9206-2

48. Schmale, D. G., Wood-Jones, A. K., Cowger, C., Bergstrom, G. C., and Arellano, C. 2011. Trichothecene genotypes of Gibberella zeae from winter wheat fields in the eastern USA. Plant Pathol. 60:909-917.

49. Sobrova, P., Adam, V., Vasatkova, A., Beklova, M., Zeman, L., and Kizek, R. 2010. Deoxynivalenol and its toxicity. Interdiscip. Toxicol. 3:94-99.

50. Southern, E. M. 1975. Detection of specific sequences among DNA fragments separated by gel-electrophoresis. J. Mol. Biol. 98:503-508.

51. Spolti, P., Del Ponte, E. M., Cummings, J. A., Dong, Y., and Bergstrom, G. C. 2014. Fitness attributes of Fusarium graminearum isolates from wheat in New York possessing a 3-ADON or $15-\mathrm{ADON}$ trichothecene phenotype. Phytopathology 104:513-519.

52. Starkey, D. E., Ward, T. J., Aoki, T., Gale, L. R., Kistler, H. C., Geiser, D. M., Suga, H., Tóth, B., Varga, J., and O'Donnell, K. 2007. Global molecular surveillance reveals novel Fusarium head blight species and trichothecene toxin diversity. Fungal Genet. Biol. 44:1191-1204.

53. Strausbaugh, C. A., Overturf, K., and Koehn, A. C. 2005. Pathogenicity and real-time PCR detection of Fusarium spp. in wheat and barley roots. Can. J. Plant Pathol. 27:430-438.

54. Suga, H., Gale, L. R., and Kistler, H. C. 2004. Development of VNTR markers for two Fusarium graminearum clade species. Mol. Ecol. Notes 4:468-470.

55. Tamura, K., Stecher, G., Peterson, D., Filipski, A., and Kumar, S. 2013. MEGA6: Molecular evolutionary genetics analysis version 6.0. Mol. Biol. Evol. 30:2725-2729.

56. Thiel, P. G., Marasas, W. F. O., Sydenham, E. W., Shephard, G. S., Gelderblom, W. C. A., and Nieuwenhuis, J. J. 1991. Survey of fumonisin production by Fusarium species. Appl. Environ. Microbiol. 57:1089-1093.
57. Tuite, J. 1969. Plant Pathological Methods. Burgess Publishing Company, Minneapolis, USA., $239 \mathrm{pp}$.

58. Von der Ohe, C., Gauthier, V., Tamburic-Ilincic, L., Brule-Babel, A., Dilantha Fernando, W. G., Clear, R., Ward, T. J., and Miedaner, T. 2010. A comparison of aggressiveness and deoxynivalenol production between Canadian Fusarium graminearum isolates with 3-acetyl and 15-acetyldeoxynivalenol chemotypes in field-grown spring wheat. Eur. J. Plant Pathol. 127:407-417.

59. Wang, J.-H., Ndoye, M., Zhang, J.-B., Li, H.-P., and Liao, Y.-C. 2011 Population structure and genetic diversity of the Fusarium graminearum species complex. Toxins 3:1020-1037.

60. Wang, X. L., Cui, Y. F., Fan, F. Y., Song, Y. L., Ren, J. P., Meng, Q. L., Xu, W. J., and Jiang, L. H. 2010. Phylogenetic, carbendazim sensitivity, and mycotoxin genotype analyses of Fusarium graminearum complex species isolated from wheat Fusarium head blight in China. J. Phytopathol. 158: 576-578.

61. Ward, T. J., Bielawski, J. P., Kistler, H. C., Sullivan, E., and O’Donnell, K 2002. Ancestral polymorphism and adaptive evolution in the trichothecene mycotoxin gene cluster of phytopathogenic Fusarium. Proc. Natl. Acad. Sci. USA 99:9278-9283.

62. Ward, T. J., Clear, R. M., Rooney, A. P., O'Donnell, K., Gaba, D., Patrick, S., Starkey, D. E., Gilbert, J., Geiser, D. M., and Nowicki, T. W. 2008. An adaptive evolutionary shift in Fusarium head blight pathogen populations is driving the rapid spread of more toxigenic Fusarium graminearum in North America. Fungal Genet. Biol. 45:473-484.

63. Wu, X., Murphy, P., Cunnick, J., and Hendrich, S. 2007. Synthesis and characterization of deoxynivalenol glucuronide: its comparative immunotoxicity with deoxynivalenol. Food Chem. Toxicol. 45:1846-1855.

64. Xue, A. G., Ho, K. M., Butler, G., Vigier, B. J., and Babcock, C. 2006 Pathogenicity of Fusarium species causing head blight in barley. Phytoprotection 87:55-61.

65. Yli-Mattila, T., Gagkaeva, T., Ward, T. J., Aoki, T., Kistler, H. C., and O'Donnell K. 2009. A novel Asian clade within the Fusarium graminearum species complex includes a newly discovered cereal head blight pathogen from the Russian Far East. Mycologia 101:841-852.

66. Zeller, K. A., Bowden, R. L., and Leslie, J. F. 2003. Diversity of epidemic populations of Gibberella zeae from small quadrats in Kansas and North Dakota. Phytopathology 93:874-880.

67. Zeller, K. A., Bowden, R. L., and Leslie, J. F. 2004. Population differentiation and recombination in wheat scab populations of Gibberella zeae from the United States. Mol. Ecol. 13:563-571.

68. Zhang, Y., Xu, J., Chen, W., Feng, J., Zhang, H., Van der Lee, T., Waalwijk, C., and Xu, J. 2012. Population analysis of the Fusarium graminearum species complex from wheat in China show a shift to more aggressive isolates. PLoS ONE 7(2) e31722. Online publication doi:10.1371/journal.pone.0031722 